Kibalchenko, I., Eksakusto, T., \& Chegodaeva, K.(2021). Peculiarities of the students' conceptual structures and basic beliefs correlation, International Journal of Cognitive Research in Science, Engineering and Education (IJCRSEE), 9(1), 37-50.

Original scientific paper

UDK:

Received: January, 21.2021.

159.953/.955.072-057.875(470)

Revised: March, 17.2021.

159.947.5.072-057.875(470)

Accepted: March, 26.2021.

316.642.3-057.875(470)

doi: $10.23947 / 2334-8496-2021-9-1-37-50$

\title{
Peculiarities of The Students' Conceptual Structures and Basic Beliefs Correlation
}

\author{
Kibalchenko Irina ${ }^{1 *}$, Eksakusto Tatiana ${ }^{2}$, Chegodaeva Klavdia ${ }^{3}$
}

\begin{abstract}
'Department of psychology and life safety, Federal State-Owned Educational Autonomy Establishment of Higher Education «Southern Federal University», Taganrog, Russian Federation, e-mail: kibalirina@sfedu.ru

2Department of psychology and life safety, Federal State-Owned Educational Autonomy Establishment of Higher Education «Southern Federal University», Taganrog, , Russian Federation, e-mail: exakusto@sfedu.ru

${ }^{3}$ Fronted-defeloper, freelance, Russian Federation, e-mail: k.bobinskaya@gmail.com
\end{abstract}

\begin{abstract}
The research is basically aimed at studying the students' conceptual structure and basic beliefs being formed and correlated as well as at their classifying in accordance with the level of integration and coherence. The students' conceptual structures and basic beliefs are analyzed in the article; special attention is paid to semantic, categoric and conceptual abilities coherence (homogeneity) and formedness. If speaking about methodology of the research, it includes theoretical and empirical methods. Theoretical, cluster and factor analyses as well as the Kruskal-Wallis rank sum test allowed us to define 5 clusters (groups) with low, medium-low, mean (average), high and extraordinary indices of the students' conceptual structure and basic beliefs formedness. These clusters significantly differ at levels from $p \leq 0.01$ to $p \leq 0.05$. The students' conceptual structure and basic beliefs correlations form the level systems classification characterized by different coherence of these levels. It is sufficient to conclude that different basic beliefs are the core of the students' subjective inner world and are correlated with these beliefs conceptual structures specificity. The attained results prove the phenomenon of the intellectual resource "splitting": the intellectual resource can split into productive and non-productive components in case of high-level intelligence, i.e. if the intelligence level is too high the intellectual resource and its basic components can be insufficiently formed and/or poorly developed.
\end{abstract}

Keywords: Conceptual structures, basic beliefs, correlations classification.

\section{Introduction}

Since the notion "basic beliefs" was defined by S. Epstein in his cognitive-experimental theory and by R. Janoff-Bulman's personal basic beliefs cognitive concept, lots of researchers use it as the basic variable to explain the features of a person's surrounding world events perception and to define persons behavior peculiarities. The way the persons interpret the events that take place in their lives (i.e. mentioning the ability to gain new experience, paying attention to any possibility for personal development or just perceiving them as unfair or an obstacle) has a great influence on their well-being, success and being satisfied with their life or not. This aspect is particularly relevant for young people who are in their early stages of adulthood. At the same time those young people who perceive the world as absolutely unfair and the relations with others - hostile or adversarial, have a low self-esteem and value their opportunities at a low level are of a great need in psychological support because in conditions of personal formation these people can be on the outside of an active and successful interaction with the world, with themselves and others. On the other hand, people with the well-developed sense of purpose and positive basic beliefs are of great importance for society; they help the society to be in progress. That is why psychological and pedagogical support of the young people having negative basic beliefs is one of the most important and modern trends in psychological work. But this help implementation requires understanding the mechanisms and predictors of basic beliefs forming. These predictors can include cognitive resource (aimed at processing information, i.e. defining the character of a human's personal perception of the surrounding world). Thus, the research is aimed at studying the connection of conceptual structures (as the basic part of the cognitive resource) and basic beliefs of the young people (students).

"Corresponding author: kibalirina@sfedu.ru

(c) (i) 2021 by the authors. This article is an open access article distributed under the terms and conditions of the Creative Commons Attribution (CC BY) license (https://creativecommons.org/licenses/by/4.0/). 
It has already been mentioned that basic beliefs are the person's hierarchically organized cognitive and emotional implicit opinions, judgments and knowledge, which help the person to perceive the events of the surrounding world (Kibal'chenko and Eksakusto, 2020; Padun and Kotel'nikova, 2008). Most of the researches carried out and connected with the basic beliefs and their impact on perceiving the events of person's life let us make the following conclusions.

First of all, persons' basic beliefs are connected with the PTSD symptoms severity condition, with the quantity and types of traumatic events as well as with the ability of post traumatic growth. The maximum effect while working with victims is observed on the level of basic beliefs about the surrounding world functioning (Bulman and Timko, 2020). Those people who had any traumatic event (e.g. physical/somatic disease, active service/commitment, lost their relatives, loss of their motherhood and/or home (refugees)) in their lives are characterized by such basic beliefs as "Benevolence of the World", "Benevolence of People" and "Luck" being negatively expressed (Ter Heide, Sleijpen and van der Aa, 2017; Dekel at all., 2004; Ward and Plagnol, 2019). It is found out that a long period of the existential stress impact bringing person to depression is accompanied by negative attitude to benevolence of the world, being sure that the world is unjust and uncontrolled as well as by the low self-esteem and poor belief in commitment to succeed (Załuski, 2015; Padun and Kotel'nikova, 2012). The basic beliefs are proved to be the so called "mediator" between traumatic event and dissociation and the strongest connection of these problems is found with the beliefs of the world benevolence and self-esteem (Lilly, 2011). The research made by Goldenberg, I., Matheson, K. shows that posttraumatic stress symptoms are poorly expressed in a group of those people who had any traumatic event in their lives but still have positive basic beliefs of the world; these people are likely to use active and constructive strategies in challenges overcome and problems solving (Goldenberg and Matheson, 2005). Some people having traumatic events (splitting personal basic beliefs of themselves, world and others) are as well characterized by the effect or posttraumatic growth: they are able to reconsider their basic beliefs after the traumatic event, i.e. the integrative system of beliefs can be reconstructed (Mazor, Gelkopf and Roe, 2020; Lahav, Bellin and Solomon, 2016).

Secondly, basic beliefs are the basis of the human's subjective well-being, allowing human to be stable (robust), satisfied and successful in different spheres of life and happy while interacting with others. Some researches reflect the idea of people having stable positive basic beliefs of the benevolence of the world, being characterized by the higher level of well-being in general and in separate spheres of their lives (health, social relations, educational activity, etc.) (Dzuka and Dalbert, 2006; Belyaeva, Kyoppel' and 2018; Shelegina, 2018; Tsvetkov, 2020; Lifshits, 2019; Elshanskij, 2020). On the other hand, external negative influence (bullying, mobbing) can destroy positive basic beliefs of self-esteem, other people (and relations with them) estimation, benevolence of the world and bring person to subjective ill-being and stress reactions (Mikkelsen, 2001). It is also found out that basic beliefs of the benevolence of the world and its controllability can sufficiently define the processes of adaptation and challenges overcome. Taking physically challenged people as an example, it was proved that the basic beliefs destruction can lead to longer period of rehabilitation and adaptation (Monden et al., 2016). Herewith, being stable (robust) and having positive basic beliefs, in case of any traumatic event, people continue having positive emotions towards the world around and have just insufficient functional disturbance (Bonanno, 2004).

Modern researches show that the basic beliefs (hope, belief in a just and controlled world and events, etc.) determine the aim of life and being satisfied with it; and if the levels of these factors grow up the level of stress and anxiety caused by Covid-19 grows down. Trzebiński, J., Cabański, M., Czarnecka, J. Z. suppose that basic beliefs can be called "buffer" redeeming from anxiety, unproductive thinking and making decisions in case of an unpredictable threat (Trzebiński, Cabański and Czarnecka, 2020).

Taking into account the importance of basic beliefs for a person's world and various events perception, separate and few studies are also aimed at finding the predictor of developing such faiths as belief in a just world, in a value of human selfhood, in controllability of the world. These studies suggest that these predictors include conceptual thinking and conceptual structures forming the basis of a person's intellectual resource.

Nowadays the problem of conceptual thinking and conceptual structures of personality is the most popular topic in psychological and interdisciplinary research for scientists and researchers around the world. Theoretical analysis of this problem studying basic approaches helps to make a suggestion that the most promising one is to study conceptual thinking and its structural features as a form of an individual intelligence integral work as a whole; the information processing elaboration as well as regulation and motivation are considered being core components of intellectual activity (Pulyaeva and Nevryuev, 2020; Gavrilova and Leshcheva, 2013; Volkova and Gusev, 2016; Maksimović and Osmanović, 2019). The conceptual abilities forming conceptual structures play a leading role among different types of cognitive abilities and are represented in three forms: semantic abilities (digestion, storage and updating of the verbal signs content); categoric (categorical signs, characterized by different 
generality degrees, separating and operating) and conceptual abilities (new mental contents generating).

This research studies conceptual abilities as the most importantones among all conceptual structures.

Theoretical analysis showed that person's conceptual abilities are manifested in categorization, explanation, interpretation, in a predominant cognitive style and reflect the features of a person's cognitive assessment of the world around him/her (events, situations, etc.) (Quillien, 2020). Understanding and analyzing the events and transformationstaking place is determined by the level of conceptualabilities developmentand leads toan understanding of correlations being the bases of thesetransformations/changes(McCaslinand Kilrea, 2019).

For example, the study held by L. Shi and co-authors showed that the higher the mental capacity, adaptability and flexibility of a human and his/her informational connections are, the higher his/her well-being is (Shi, et al., 2018). It was also found that cognitive assessments of an upcoming event (their favorability in terms of self-efficacy, control and, optimism) have an impact on coping with the situation (distress, being satisfied with decision-making) (Major et al., 1998).

It should be emphasized that conceptual abilities are the key ones among intellectual abilities; they are the mental qualities making conditions for new (absent in actual circumstances or in absorbed basic knowledge) mental contents generating. The following criteria are identified as conceptual abilities: identification of implicit signs and connections; creating new beliefs and ideas; constructing a variable number of the situation versions, etc. (Holodnaya and Hazova, 2017). Conceptualization brings about managing own personal resources and "creating" new ones (Hazova, 2016).

The fact of the conceptual structures (and, in particular, conceptual abilities) being connected and correlated with basic beliefs (being a part of the personality worldview) is confirmed by separate studies conducted in the context of the psychology of intelligence and the intellectual resource of personality (Holodnaya, 2019; Hazova, 2018; Trifonova, 2016; Artemova and Lezhnina, 2016). The authors found out that the degree of conceptual abilities developmentand basic beliefs character determine the overall success of person (Kibal'chenko, Eksakusto and Istratova, 2017). We have also identified "harmonious" models of the basic beliefs productive aspects intellectual predictors. For example, the self-control (SC) predictors system includes: directly related styles "Reflexivity", "Abstract conceptualization", "Field independence" and the inversely related style "Rigidity". All styles of this system, taking into account theinverse relation with "Rigidity", create a harmonious unit for the degree of self-control assessing (Kibal'chenko and Eksakusto, 2020).

TheresearchcarriedoutbyS.Jeavons, K.M. Greenwood pointsouttheconnection ofbasicassumptions and cognitive appraisal; at the same time factor structures of strategy, attributions and cognitive assessment were incomplete and unstable that demands additional check of results (Jeavons and Greenwood, 2007). Correlation of the intellectual and personal resources represented by basic beliefs shows that the higher intelligence indices are, the lower the faith in controllable world is, as well as the average intelligence level determines belief of benevolence of the world and a high self-worth index (Budakova and Matsuta, 2016).

The relations between conceptual abilities and basic beliefs form a dyad of the foundations of a person's value-sense and conceptual view of oneself, other people and the world as a whole; this dyad depends on coherence (homogeneity) of conceptual abilities and basic beliefs indices being well/poorly formed (Kibal'chenko, Istratova and Eksakusto, 2019). The study of this connection is of great importance in terms of its manifestation peculiarity among young people (students) being a special group characterized by different level of intellectual and personal resources integration; this difference depends on age (integrating ideal and real during mental activity) and social (low vital capacity, contradictory basic beliefs) features.

In our opinion, the results of the analysis and the assumptions put forward provide an empirical study of the conceptual structures and basic beliefs correlations. It is therefore important to define connection between conceptual structures and basic beliefs empirically. Hypothetically, the relations between conceptual structures and basic beliefs form systems with different coherence (homogeneity) and have their own features. These differences depend on the fact that different basic beliefs, being the core of the human subjective world, are connected with the special nature of individual conceptual structures.

\section{Materials and Methods}

The following methods and techniques were used to define the conceptual abilities and basic beliefs indices:

1. Conceptual categoric abilities assessment: "Three words meaning generalization" (Holodnaya et al., 2019).

2. Semantic and conceptual abilities assessment: "Problem statement", "Pictorial and verbal interpretation", "Concept cognitive content" (Holodnaya, 2019). "Resource" is used as a key cue word. 
3. The following methods were used for each ability unit: "Words free sorting test" (Kolga); "Conceptual synthesis" (Holodnaya et al., 2019; Holodnaya, 2019).

4. World assumptions scale (WAS) (R. Janoff-Bulman) was used to study such indices as "Benevolence of the World", "Meaningfulness of the World" and "Self-Worth".

5. The methods of the results processing and interpreting are as follows: hierarchical cluster analysis with more than two variables was used to define coherent (homogeneous) groups; statistic criteria (Kruskal-Wallis one-way analysis of variance) and Cluster method were used to define withingroups linkage and factor analysis in SPSS (IBM SPSS Statistics Subscription Trial for Mac OS).

One hundred and thirty-four Southern Federal University students (76 males and 58 females) took part in the research. Average age of the respondents was 20.5 years (19-22 years old). 55.7 per cent male and 44.3 per cent female students.

\section{Results}

According to the purpose of the research and the hypotheses formulated, the diagnostic results were used for hierarchic cluster analysis at the first stage of the study; the analyses included the following students' data: indices of the conceptual thinking and basic beliefs formedness level; conceptual synthesis; the concept generality degree; ability to identify variety of concepts content private and common features; ability to match concepts to categoric and class-descriptive commonalities; the students' basic beliefs level indices.

Independent clusters - homogeneous (coherent, congeneric) groups, shown in fig.1, were defined during the process of clustering.
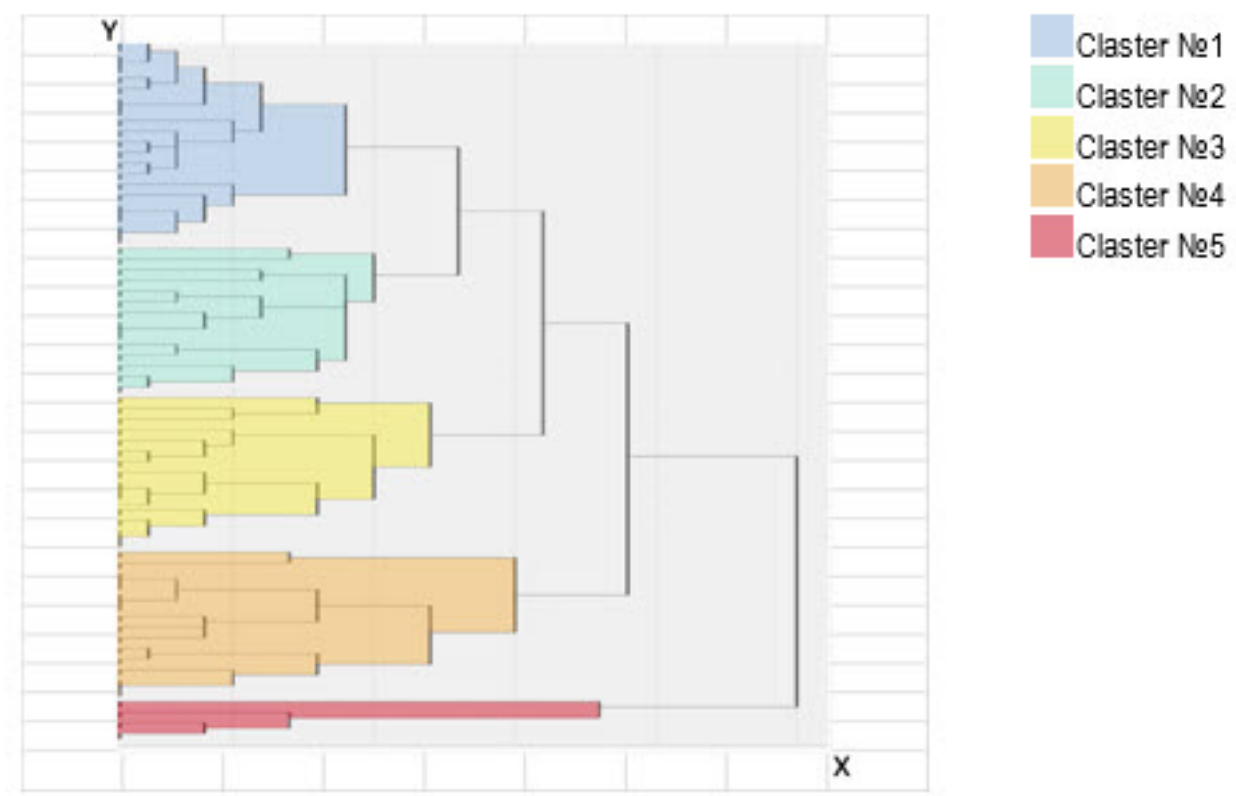

Figure 1. Tree diagram of the analysis results clustering

Each cluster is a group including results of students with maximally related conceptual structures and basic beliefs formedness levels. The first cluster includes 29.3 per cent of students; the mean observation is 2.32 points in conceptual structures formedness and 2.21 points in basic beliefs formedness level.

The second cluster includes 16.7 per cent of students with the following mean values: 3.2 points in conceptual structures and 2.9 - in basic beliefs formedness level.

The third one is represented by 31.4 per cent of students, characterized by 3.4 points in conceptual structures formedness level and 3.31 - in basic beliefs formedness level.

The fourth cluster includes 16.4 per cent of students with 4.4 and 4.39 points in conceptual structures and basic beliefs formedness level.

The fifth cluster is thin on the ground ( 6.3 per cent of students), but significantly differs from all previous ones in conceptual structures and basic beliefs formedness level. The mean value here is 6.00 and 5.02 points respectively.

Thus, five results "casts" were defined taking into account clusters quantitative content; this fact 
helped us to identify five homogeneous groups of students and to study peculiarities of the conceptual structures and basic beliefs correlation.

All the students were split up into five sampling groups in accordance with the defined clusters; these sampling groups differ in a level of students' conceptual structures and basic beliefs formedness: No. 1);

- group characterized by low level of conceptual structures and basic beliefs formedness (cluster

- group with medium-low indices (cluster No. 2);

- group with medium (average) indices (cluster No. 3);

- group characterized by high indices (cluster No.4);

- and a group with extraordinary indices of conceptual structures and basic beliefs formedness level (cluster No. 5).

The students are symmetrically grouped into clusters in accordance with the formedness levels, but their quantity in these groups is asymmetrical.

The statistic processing of the results was held on the second step of the research; the KruskalWallis one-way analysis of variance was used to analyze five groups (clusters) according to the following indices: categoric generalization; conceptual synthesis; involuntary categorization; cognitive content of the "resource" concept; pictorial and verbal interpretation of the "resource" concept; the "resource" concept problem statement and the students' basic beliefs formedness level indices.

The groups do not differ in three variables of the eleven ones, i.e. equality of these groups is 27.2 per cent, but in 72.8 per cent these groups (clusters) of students significantly differ. Three variables connecting the clusters are as follows:

- associative categorization, i.e., awareness of the categories meanings, ability to use variety of concepts (categoric generalization - CG). This fact proves that all the students participating in the research are characterized by a very similar level of the categories meaning awareness;

- the degree of semantic context complexity (conceptual synthesis - CS), i.e. general idea of the described "resource" concept;

- the level of the conceptual experience formedness in a structure of the students conceptual thinking (problem statement - PS), i.e., the abilities to tease out the variety of private and general features and to match concepts to categoric and class-descriptive commonalities do not differ significantly.

Statistically significant differences are teased out in accordance to the following characteristics:

- involuntary categorization - IC (the levels of involuntary intellectual control) (hemp. $=13.76$, $p \leq 0,01)$. The better the conceptual structures and basic beliefs are formed, the higher the level of involuntary categorization is;

- the levels of the "resource" concept cognitive content (CC) formedness (hemp. $=23.92, p \leq 0.01$ ) as a stimulus reflecting the students' personal success. This data show that the students of different groups defined during the research are characterized by different levels of awareness of personal success concepts; by different understanding and using the gained experience for each concept. The better the conceptual structures and basic beliefs are formed the higher the level of the students' awareness of personal success concepts and their ability to use their experience are;

- integral conceptual structures including the pictorial and verbal interpreting (PVI) of the "resource" concept (hemp. $=7.41, p \leq 0.05$.), i.e., the students' ability to express personal experience through mental images of this concept is formed differently. The better the conceptual structures and basic beliefs are formed the higher the level of ability to express personal experience through mental images of the concept is;

- general index of the conceptual thinking (CT) (hemp. $=57.08, p \leq 0,01$ ).

Five groups were analyzed diagnostically and in accordance with basic beliefs major characteristics; the results of this analysis defined significant differences in the following indices:

- general attitude to the "benevolence of the world", "just of the world" and "benevolence of people" (BW) (hemp. = 21.89, ps0,01);

- general attitude to world understanding, events controllability, being just and occasional (WU) (hemp. $=22.55, \mathrm{p} \leq 0,01$ );

- beliefs of self-worth, self-control and ability to control and to rule the events (SW) (hemp. $=22.77$, $\mathrm{p} \leq 0,01$; ;

- basic beliefs formedness mean value $(\mathrm{BB})$ (hemp. . $=53.53, \mathrm{p} \leq 0,01$ ).

These differences show that the students included in the groups defined by cluster analysis are characterized by dissimilarities in "subjective core of personality", general view of the world, development characteristics harmony and balance and basic beliefs formedness. 
The results of the statistic analysis prove our suppositions:

- the students' semantic, categoric and conceptual abilities coherence with their basic beliefs differs in levels;

- the students whose basic beliefs are well-formed (vs. the students whose basic beliefs are not formed or poorly-formed) are characterized by high level of conceptual structures formedness.

The differences defined at the second stage of the research helped us to carry the third step and to study the peculiarities of the conceptual structures and basic beliefs correlation in each group (cluster).

The "resource" stimulus was studied at the stage of factor analysis as a general ability of a person preconditioning success. This fact helped to lower the number of variables and to define coherence (homogeneity) of the students' conceptual abilities and basic beliefs formedness indices.

Factorization of the first group of students (with low level of conceptual structures and basic beliefs formedness) defined as a cluster No. 1 is as follows: the summary dispersion as a result of factor analysis is 68.7 per cent. A full three-component factor structure resulted from rotation (varimax with Kaiser Normalization); this structure is characterized by direct correlation prevailing, but also includes two indices with inverse correlation (Table 1).

\section{Table 1}

Factor structure of the students' semantic, categoric and conceptual abilities indices coherence with their basic beliefs ones (group 1 - with low results)

\begin{tabular}{cccc}
\hline \multirow{2}{*}{ Characteristics } & \multicolumn{3}{c}{ Components in group 1 } \\
\cline { 2 - 4 } F1 & F2 & F3 \\
\hline CG & $\mathbf{0 , 7 9}$ & $-0,29$ & $-0,04$ \\
IC & 0,44 & $\mathbf{0 , 5 1}$ & $-0,40$ \\
CC & 0,58 & 0,23 & $-\mathbf{0 , 6 3}$ \\
PS & 0,25 & $-\mathbf{0 , 6 5}$ & 0,08 \\
PVI & 0,00 & 0,39 & $\mathbf{0 , 7 0}$ \\
BW & 0,25 & $\mathbf{0 , 6 8}$ & 0,23 \\
WU & $\mathbf{0 , 8 2}$ & $-0,15$ & 0,26 \\
SF & $\mathbf{0 , 9 2}$ & 0,07 & 0,14 \\
Percentage load & 34,7 & $-0,10$ & 0,19 \\
\hline
\end{tabular}

F1 is maximally loaded, crystallizing. It includes directly correlated indices of such variables as categoric generalization and basic beliefs general direction indices (i.e. belief in benevolence of the world, benevolence of people, the good prevailing over the evil, events controllability and just, belief in ability to control the events).

F2 includes direct variables (conceptual synthesis, "resource" mental representation) and inverse index of this concept awareness. This distribution proves disharmonic, discordant correlation between conceptual structures and mental abilities of these students; i.e. the "resource" concept pattern is formed, but these students' awareness of this concept field content is poorly-developed because they have lack of necessary experience in using the "resource" concept content.

F3 includes the directly and inversely correlated indices of the "resource" concept experience and the form of involuntary intellectual control. Thus, the students of this group are characterized by indices narrow equivalence range (analyticity) if they have a potential in problem statement. This fact indicates 
lower rates of involuntary and associative memorizing; as well as the ability to operate better with accurate rather than abstract conceptual structures.

The students of the second cluster (group 2) characterized by medium-low conceptual structures and basic beliefs formedness indices showed the following results: the summary dispersion as a result of factor analysis is 76.5 per cent; this is a fact of integrity of the results.

The four-component full factor structure (Table 2) resulted from the analysis; the character of correlations is mixed (direct and inverse ones). The first three factors are of great interest and the fourth one is unstable.

\section{Table 2}

Factor structure of the students' semantic, categoric and conceptual abilities indices coherence with their basic beliefs ones (group 2 - with medium-low results)

\begin{tabular}{ccccc}
\hline \multirow{2}{*}{ Characteristics } & \multicolumn{4}{c}{ Components } \\
\cline { 2 - 5 } & F1 & F2 & F3 & F4 \\
\hline CG & $-0,02$ & $\mathbf{0 , 6 2}$ & $-0,01$ & 0,48 \\
CS & $-0,14$ & $\mathbf{0 , 8 7}$ & 0,16 & $-0,04$ \\
IC & 0,39 & $\mathbf{0 , 8 0}$ & $-0,10$ & 0,05 \\
CC & 0,37 & $-0,16$ & $-\mathbf{0 , 7 6}$ & 0,03 \\
PS & $-0,86$ & $-0,08$ & 0,12 & 0,26 \\
PVI & $-0,28$ & 0,15 & 0,11 & $\mathbf{0 , 7 9}$ \\
BW & 0,24 & $-0,07$ & $\mathbf{0 , 8 7}$ & 0,06 \\
WU & $\mathbf{0 , 5 4}$ & $-0,18$ & $-0,30$ & 0,53 \\
SF & $\mathbf{0 , 9 1}$ & 0,08 & 0,13 & $-0,04$ \\
Percentage load & 25,5 & 46,4 & 63,1 & 76,5 \\
\hline
\end{tabular}

F1 includes characteristics of conceptual abilities ("resource" problem statement) inversely correlated with basic beliefs (meaningfulness of the world and self-worth) characteristics. This factor reflects the gaps of the students' individual intellectual and personal resource integration.

F2 includes semantic, categoric and conceptual abilities (such as categoric generalization, conceptual synthesis and involuntary categorization) formedness indices. Thus, the conceptual structures are differentiated in a structure of intellectual and personal resource; this fact correlates with the 1st factor gaps.

F3 shows an inversely directed correlation between the belief of the benevolence of the world and the "resource" concept cognitive content. The contradictory correlation between the belief in the benevolence of the world and awareness of personal current and potential opportunities leads to the conclusion that there are some gaps in adaptive potential of the students included into this group. Moreover, they are unable to manage their intellectual and personal resource and the events constantly.

F4 contains only one variable and is unstable.

If speaking about the students included into the 3rd group (with mean (average) indices of the conceptual structures and basic beliefs formedness) and factorization of the analysis results, we can say that the summary dispersion here is 71.0 per cent. The three-component full factor structure, characterized by direct connection, resulted from rotation (Table 3). 
Table 3

Factor structure of the students' semantic, categoric and conceptual abilities indices coherence with their basic beliefs ones (group 3 - with mean (average) results)

\begin{tabular}{cccc}
\hline \multirow{2}{*}{ Characteristics } & \multicolumn{3}{c}{ Components } \\
\cline { 2 - 4 } CG & $\mathbf{0 , 8 6}$ & 0,00 & $-0,21$ \\
\hline CS & 0,06 & $-0,10$ & $\mathbf{0 , 8 0}$ \\
IC & $\mathbf{0 , 7 0}$ & $-0,29$ & 0,12 \\
CC & 0,16 & 0,10 & $\mathbf{0 , 8 2}$ \\
PS & $-0,15$ & $\mathbf{0 , 8 4}$ & 0,07 \\
PVI & 0,16 & $\mathbf{0 , 7 8}$ & $-0,04$ \\
BW & $\mathbf{0 , 7 4}$ & 0,26 & 0,44 \\
WU & $\mathbf{0 , 7 3}$ & 0,14 & 0,39 \\
SF & $\mathbf{0 , 6 8}$ & 0,07 & 0,54 \\
Percentage load & $31,8 \%$ & $48,7 \%$ & $\mathbf{7 1} \%$ \\
\hline
\end{tabular}

F1 is crystallizing in this group and includes five characteristics: three basic beliefs indices and categoric abilities of associative and involuntary categorization. This factor is characterized by basic beliefs and conceptual structures integration.

F2 includes indices of the "resource" notion conceptual experience and mental representation, i.e., the students of this group create (plan) their resource from the point of view of understanding.

F3 includes the indices of the "resource" notion conceptual synthesis and cognitive content and amplify the indices of the second factor.

It should be mentioned that the factor structure of the students' semantic, categoric and conceptual abilities coherence with their basic beliefs is harmonic; i.e., the conceptual structures and basic beliefs of the students included into this group systematically form and develop and create an integrated individual personal resource. Students' success and their abilities and qualities further development directly depend on the level of personal resource formedness.

The students of the fourth cluster (group 4) characterized by high conceptual structures and basic beliefs formedness indices showed that the summary dispersion here is 81.3 per cent.

The three-component full factor structure resulted from rotation (Table 4). 


\section{Table 4}

Factor structure of the students' semantic, categoric and conceptual abilities indices coherence with their basic beliefs ones (group 4 - with high results)

\begin{tabular}{cccc}
\hline \multirow{2}{*}{ Characteristics } & \multicolumn{3}{c}{ Components } \\
\cline { 2 - 4 } CG & $-\mathbf{0 , 8 6}$ & 0,12 & $-0,03$ \\
CS & 0,06 & 0,94 & 0,08 \\
IC & 0,29 & 0,21 & $\mathbf{0 , 8 8}$ \\
CC & $\mathbf{0 , 8 2}$ & $-0,10$ & 0,45 \\
PS & $-0,54$ & $\mathbf{0 , 7 0}$ & $-0,18$ \\
PVI & 0,19 & $-0,02$ & $\mathbf{0 , 9 3}$ \\
BW & 0,08 & $\mathbf{0 , 6 6}$ & 0,24 \\
WU & $-0,04$ & 0,57 & $\mathbf{0 , 6 6}$ \\
SF & $\mathbf{0 , 9 0}$ & 0,28 & 0,14 \\
Percentage load & 29,3 & 54,7 & 81,3
\end{tabular}

F1 combines such directly correlated indices as self-worth, ability to control the events and luck, "resource" concept cognitive content and inversely correlated index of categoric generalization. That means that the students point out different sufficient signs of the "resource" concept in different situations.

Two other factors have the signs of intellectual and personal resource integration.

F2 is represented by direct correlation of conceptual synthesis, conceptual experience concerning the "resource" stimulus, general attitude to the benevolence of the world, belief in good prevailing over evil and good people number prevailing over bad one.

F3 includes directly correlated indices of involuntary categorization, the "resource" concept mental representation and attitude to meaningfulness of the world.

The fifth group (it 6.3 per cent of all students and is characterized by an extraordinary indices of the conceptual structures and basic beliefs formedness level) results factorization showed the summary dispersion of 100 per cent. The three-component factor structure resulted from rotation (Table 5). 


\section{Table 5}

Factor structure of the students' semantic, categoric and conceptual abilities indices coherence with their basic beliefs ones (group 5 - with extraordinary results)

\begin{tabular}{cccc}
\hline \multirow{2}{*}{ Characteristics } & \multicolumn{3}{c}{ Components } \\
\cline { 2 - 4 } & F1 & F2 & F3 \\
\hline CG & $-0,67$ & $\mathbf{0 , 6 5}$ & 0,36 \\
CS & $-0,06$ & $\mathbf{0 , 9 8}$ & $-0,16$ \\
IC & $\mathbf{0 , 9 6}$ & 0,28 & $-0,08$ \\
CC & $-0,15$ & $-\mathbf{0 , 9 7}$ & 0,18 \\
PS & $-0,13$ & 0,44 & $-\mathbf{0 , 8 9}$ \\
PVI & $\mathbf{0 , 9 8}$ & $-0,06$ & $-0,17$ \\
BW & 0,63 & $\mathbf{0 , 6 9}$ & 0,36 \\
WU & $\mathbf{0 , 9 7}$ & $-0,05$ & 0,23 \\
SF & $-0,13$ & 0,10 & $\mathbf{0 , 9 9}$ \\
Percentage load & 41,4 & 75,8 & 100 \\
\hline
\end{tabular}

F1 consists of such directly correlated indices as general attitude to the meaningfulness of the world, "resource" concept mental representation, involuntary categorization and inversely correlated categoric generalization. These students handle class-descriptive categories found and defined on their own; they call these categories in their own way through the lens of sufficient index and sign. At the same time, their attitude to the world is meaningful and they structure the image of their intellectual and personal resource.

F2 includes directly correlated indices of the general attitude to the benevolence of the world, conceptual synthesis and inversely correlated index of the "resource" concept cognitive content. This factor as well as the first one expresses peculiarities of the personal resource and formedness of the conceptual synthesis studied as the sign of highly-developed conceptual abilities. These abilities are a "peak" of the conceptual structures development.

F3 is formed by directly and inversely correlated indices of conceptual experience concerning the "resource" stimulus and self-worth as well as the ability to manage and control the events and luck. It can be supposed that the students of this group are not satisfied with themselves and their achievements and gains.

The results of the factor analysis let us state that each group of students is characterized by specific peculiarities of the conceptual structures and basic beliefs correlations.

\section{Discussions}

The results received during the research demonstrate that the students included into the groups revealed in a course of a groups clustering, have various levels of involuntary intellectual control; this fact is a testimony to different levels of intellectual, emotional, motivational, spiritual and axiological resources integration. Different levels of personal success awareness, realizing different levels of gained 
experience connection with the "resource" as well as different levels of conceptual experience indicate different degrees of these structures being integrated into the general intellectual and personal resource of students. Significant differences in levels the of basic beliefs formedness prove that students have absolutely different understanding of the world and of themselves. Their beliefs in positive moments predomination over bad ones, in a fact that events can be controlled and their ability to manage and control these events also differ a lot.

Thus, the fact of semantic, categoric, conceptual abilities of the students being formed and coherent with their basic beliefs is statistically confirmed, has a level-based character and can be classified. The basis for classification is the degree of the students' conceptual abilities and basic beliefs development indices coherence (homogeneity).

Five factor structures are defined in a course of studying the qualitative characteristics of the students' conceptual abilities and basic beliefs development indices coherence; these characteristics describe directions of the basic beliefs and conceptual thinking structures relations in each group.

The first group includes the students with poorly developed conceptual structures and basic beliefs. They are characterized by low semantic, categoric and conceptual abilities formation values as well as by low level of "Benevolence of the World", "Meaningfulness of the World" and "Self-Worth" concepts formation. The description of this group students' basic beliefs and conceptual structures connection shows that the general level of the basic beliefs coherence with the mental representation of the concepts regarding their success as well as with the arbitrary form of controlling the states of their individual resource is in contradiction with the involuntary control of the intellectual resource and the ability to operate on the gained experience in general. The characteristics of the students included into this group are of a narrow equivalence range ("analyticity"). These results indicate lower rates of involuntary and voluntary memorizing; cognitive rigidity, ability to operate and use accurate concept structures rather than abstract ones.

The second group includes the students with medium-low conceptual structures and basic beliefs formedness indices. This group is characterized by contradictions between "Success", "Self-Worth" and "Meaningfulness of the World" conceptual experience formedness. These students are also characterized by the lack of awareness of their capabilities to form an image of themselves in the surrounding world. They do realize and understand what is going on and what should be, but they are unable to identify themselves in these very conditions. Intellectual and personal resources are poorly integrated because conceptual structures and basic beliefs are underdeveloped, inharmonic and are contradictorily connected. These facts characterize these young people's individual resource as unstable and unformed.

The third group is represented by students with a mean (average) conceptual structures and basic beliefs formedness indices. Despite the fact that students of this group are characterized by mean (average) semantic, categoric and conceptual abilities and basic beliefs formedness indices, the character of these structures connection in this group is the most harmonious. This fact allows us to conclude that the students with mean (average) indices are characterized by steady personal and intellectual resources characteristics integration; this kind of integration is the predictor of the students' socialization success. Their conceptual abilities and basic beliefs form an integrated individual resource; the students' successful socialization and their general success depend on the level of this individual resource formedness.

The fourth group of students having high conceptual abilities and basic beliefs rates and their harmonious coherence structure, is characterized by a contradiction between the level of voluntary categorization and the ability to operate the concepts variety. This fact proves, that no matter all the variables are well formed in this group, these students make inflated demands on their resource and capabilities. In our view, it can be concluded that the students with highly developed conceptual abilities and basic beliefs are more demanding of themselves, of society and of the world as a whole. They have to alter the conceptual field standard boundaries to harmonize the intellectual and personal resource development.

The fifth group is small-numbered, but is of great interest for additional research. This is a group of students with outstanding conceptual structures and basic beliefs formedness indices. These students show the necessity of concepts standard boundaries alteration as the students of previous group. Moreover, there are some contradictions between correlations of the personal resource from gained experience with the "Benevolence of the World" and conceptual experience with "Self-Worth". Hypothetically, this contradiction suggested that such students presented their resources in an unusual and nontypical manner. Deeper integration with personal characteristics gives these students an opportunity to reflect and correlate their resources and capabilities with standard and required ones. However outstanding conditions are necessary in addition to generally accepted standards to develop the potential of students. This is due to the effect of indices "splitting" in case of very high conceptual structures results and is 
Kibalchenko, I., Eksakusto, T., \& Chegodaeva, K.(2021). Peculiarities of the students' conceptual structures and basic beliefs correlation, International Journal of Cognitive Research in Science, Engineering and Education (IJCRSEE), 9(1), 37-50.

accompanied by a number of specific effects, connected, in particular, with structural bonds breakdown.

\section{Conclusions}

The conclusion that the students' conceptual abilities and basic beliefs form their intellectual and personal resource is a result of the empirical research.

The coherence between basic beliefs and conceptual structures (semantic, categoric and conceptual abilities) formedness is conditioned by their being connected.

Thus, the students whose ideas in "Benevolence of the World", "Controllability", "Self-Worth", confidence in their ability to manage the events are well-formed and well-developed are characterized by the high conceptual structures indices. The conceptual structures of the students with malformed basic beliefs are poorly developed.

The students' abilities (semantic, categoric, conceptual) formedness coherence with their basic beliefs is level-based and represents the classification of their connections, which is reflected in structural features.

However, the structures are changed when the mean (average) results are exceeded. This scientific fact is confirmed by the phenomenon of an intellectual resource "splitting": the intellectual resource can split into productive (intellectual maturity) and non-productive components in case of the high intelligence indices. This phenomenon can lead to an intellectual resource limited development and to its basic components insufficient formedness.

Thus, the analysis of the students' conceptual structures and basic beliefs coherence was conducted for the first time; the psychological ambivalence of the students' conceptual structures and basic beliefs coherence was empirically shown and proved taking into account nonlinearity phenomena, indices interdependence and intellectual resource "splitting" into productive and non-productive components.

The group with very high conceptual structures and basic beliefs indices definition allows making an integrated idea of some students' intellectual and personal resource peculiarities and is a good basis for the following research.

\section{Acknowledgements}

We greatly appreciate contribution of the Psychology and Life Safety department staff as well as our colleagues from the Institute of Computer Technologies and Information Safety of the Southern Federal University in realizing the ideas pointed out in our article.

\section{Conflict of interests}

The authors declare no conflict of interest.

\section{References}

Artemova, Ya. V., \& Lezhnina, O. А. (2016). О взаимосвязи когнитивных фракторов и экзистенциальных оснований личности в психологической науке: открытия и проблемы [About connection of cognitive factors and existential bases of a person in Psychological Science: inventions and problems]. Human capital, 9(93), 74-79. Retrieved from https://elibrary.ru/item.asp?id=27009296

Belyaeva, Т. В., \& Kyoppel', М. V. (2018). Взаимосвязь психологического благополучия с базисными убеждениями старшеклассников [Psychological well-being correlation with basic beliefs of senior high-school students]. The Herzent University Conference on Psychology in Education, Materials of the Conference. Novgorod State University named after Yaroslav the Wise, 1(1), 158-166. Retrieved from https://elibrary.ru/item.asp?id=42937940

Bonanno, G. A. (2004). Loss, Trauma, and Human Resilience: Have We Underestimated the Human Capacity to Thrive After Extremely Aversive Events? American Psychologist, 59(1), 20-28. https://doi.org/10.1037/0003-066X.59.1.20

Budakova, A. V., \& Matsuta, V. V. (2016). Различия в показателях личностного потенциала у высокоинтеллектуальных студентов [Differences in the highly intellectual students' personal potential]. Annals of Novosibirsk State Pedagogical University, 6(34), 17-30. http://dx.doi.org/10.15293/2226-3365.1606.02

Bulman, R.J., \& Timko, C. (2020). Working with victims: Changes in the researcher's assumptive world (Book Chapter). Advances in Environmental Psychology (Volume 5): Methods and Environmental Psychology, 75-97. http://dx.doi. org/10.4324/9781003052944-3

Dekel, R., Solomon, Z., Elklit, A., \& Ginzburg, K. (2004). World assumptions and combat-related posttraumatic stress disorder. The Journal of social psychology, 144(4), 407-420. http://dx.doi.org/10.3200/SOCP.144.4.407-420

Dzuka, J., \& Dalbert, C. (2006). The belief in a just world and subjective well-being in old age. Aging and Mental Health, 10(5), 439-444. http://dx.doi.org/10.1080/13607860600637778

Elshanskij, S. P. (2020). Исследования когнитивных аспектов эфрфективности обучения в современной 
отечественной и зарубежной психологической науке. Когнитивная и мотивационно-смысловая сферы личности: монография [Research on cognitive aspects of education efficiency in modern indigenous and foreign Psychological Science. Cognitive and motivation and conceptual spheres of person: monograph]. Edited by E. B. Puchkova and E. A. Sorokoumova. Moscow: Moscow Pedagogical State University, pp. 194, 18-25. Retrieved from https://elibrary.ru/item.asp?id=43823501

Gavrilova, T. A., \& Leshcheva, I. А. (2013). Понятийные структуры знаний и когнитивный стиль. [Conceptual structures of knowledge and cognitive style]. Psychology, Journal of the Higher School of Economics, 13(1), 154-176. http://dx.doi. org/10.17323/1813-8918-2016-1-154-176

Goldenberg, I., \& Matheson, K. (2005). Inner representations, coping, and posttraumatic stress symptomatology in a community sample of trauma survivors. Basic and Applied Social Psychology, 27(4), 361-369. http://dx.doi.org/10.1207/ s15324834basp2704_9

Hazova, S. А. (2016). «Неакадемические» способности: роль и ресурсные функции в совладающем поведении субъекта [Nonacademic abilities: role and resource functions in a subject's coping behaviour]. Psychological researches, 9(49), 2. Retrieved from http://psystudy.ru/index.php/num/2016v9n49/1337-khazova49.html

Hazova, S. A. (2018). Ментальные ресурсы субъекта. Разработка понятий современной психологии [The subject's mental resources. Development of concepts in modern Psychology]. Edited by E. A. Sergienko, A. L. Zhuravlev and G. A. Vilenskaya. Moscow: Institute of Psychology of the Russian Academy of Sciences Publ., 2, 63-82. https://www. elibrary.ru/item.asp?id=35641806

Holodnaya, M. A, Trifonova, A. V., Volkova, N. E., \& Sipovskaya, Ya. I. (2019). Методики диагностики понятийных способностей [Methods of the conceptual abilities diagnostics]. Experimental Psychology, 12(3), 105-118. https://doi. org/10.17759/exppsy.2019120308

Holodnaya, М. А. (2019). Психология интеллекта. Парадоксы исследования. [Psychology of intelligence. Antinomies in research]. $3^{\text {rd }}$ edition revised and enlarged. Moscow: Urait Publ. Retrieved from https://urait.ru/bcode/422937

Holodnaya, M. A., \& Hazova, S. А. (2017). Феномен концептуализации как основа продуктивности интеллектуальной деятельности и совладающего поведения. [Conceptualization as the basis of intellectual activity and coping behaviour efficiency]. Psychological journal, 38(5), 5-17. http://dx.doi.org/10.7868/S0205959217050014

Jeavons, S., \& Greenwood, K. M. (2007). World assumptions, coping and attributions. Personality and Individual Differences, 42(7), 1427-1437. https://doi.org/10.1016/j.paid.2006.11.010

Kibal'chenko, I. A., Eksakusto, T. V., \& Istratova, O. N. (2017). Интеллектуально-личностньй ресурс субъекта развития: теоретические основы [Intellectual and personal resource of the subject of development: Theoretical foundations]. Taganrog, Southern Federal University Publ. pp. 160. Retrieved from https://elibrary.ru/item.asp?id=32323271

Kibal'chenko, I. A. Istratova, O. N., \& Eksakusto, T. V. (2019). Опьт отношений в родительской семье как предиктор интеллектуально-личностного ресурса молодых людей: монография [Parental family relations experience as a predictor of young people intellectual and personal resource: monograph]. Rostov-on-Don; Taganrog, Southern Federal University Publ. pp. 203 Retrieved from https://www.elibrary.ru/item.asp?id=41715984

Kibal'chenko A., I., \& Eksakusto V., T. (2020). Cognitive and style predictors of the students' psychological well-being. International Journal of Cognitive Research in Science, Engineering and Education, 8(1), 1-13. https://doi.org/10.5937/ IJCRSEE2001001K

Lahav, Y., Bellin, E. S., \& Solomon, Z. (2016). Posttraumatic growth and shattered world assumptions among ex-POWs: the role of dissociation. Psychiatry, 79(4), 418-432. https://doi.org/10.1080/00332747.2016.1142776

Lifshits, M. V. (2019). Взаимосвязь базовых убеждений, насыщенности жизни стрессом и психологического благополучия. [Basic beliefs connection with life filled with stress and psychological well-being]. Human capital, 10(130), $126-132$. Retrieved from https://elibrary.ru/item.asp?id=41137921

Lilly, M. M. (2011). The contributions of interpersonal trauma exposure and world assumptions to predicting dissociation in undergraduates. Journal of Trauma \& Dissociation, 12(4), 375-392. https://doi.org/10.1080/10.1080/15299732.2011 .573761

Major, B., Richards, C., Cooper, M. L., Cozzarelli, C., \& Zubek, J. (1998). Personal resilience, cognitive appraisals, and coping: an integrative model of adjustment to abortion. Journal of personality and social psychology, 74(3), 735-752. https:// doi.org/10.1037/0022-3514.74.3.735

Maksimović, J., \& Osmanović, J. (2019). Perspective of cognitive thinking and reflective teaching practice. International Journal of Cognitive Research in Science, Engineering and Education, 7(2), 1-10. https://doi.org/10.5937/IJCRSEE1902001M

Mazor, Y., Gelkopf, M., \& Roe, D. (2020). Posttraumatic growth in psychosis: Challenges to the assumptive world. Psychological Trauma: Theory, Research, Practice, and Policy, 12(1), 3. https://doi.org/10.1037/tra0000443

McCaslin, M. L., \& Kilrea, K. A. (2019). An Introduction to Transformative Inquiry: Understanding Compelling and Significant Relationships for Personal and Societal Transformation. The Qualitative Report, 24(5), 980-1000. Retrieved from https://nsuworks.nova.edu/tar/vol24/iss5/4

Mikkelsen, E. G. (2001). Workplace bullying: Why and for whom is bullying such a strain. Nordisk Psykologi, 53(2), 109-131. https://doi.org/10.1080/00291463.2001.11863991

Monden, K. R., Trost, Z., Scott, W., Bogart, K. R., \& Driver, S. (2016). The unfairness of it all: Exploring the role of injustice appraisals in rehabilitation outcomes. Rehabilitation psychology, 61(1), 44. https://doi.org/10.1037/rep0000075

Padun, M. A., \& Kotel'nikova, A. V. (2012). Психическая травма и картина мира: теория, эмпирия, практика. Монографрия [Psychological trauma and the picture of the world: theory, empiricism and practice. Monograph]. The prospects of Psychology. Moscow: Institute of Psychology of the Russian Academy of Sciences Publ., pp. 206. Retrieved from https://www.elibrary.ru/item.asp?id=19135345

Padun, M. A., \& Kotel'nikova, A. V. (2008). Модификация методики исследования базисных убеждений личности P. Яноффр-Бульман [Modification of basic personality beliefs research method of R. Janoff-Bulman]. Psychological journal, 29(4), 98-106. Retrieved from https://elibrary.ru/item.asp?id=11032506

Pulyaeva, V. N., \& Nevryuev, A. N. (2020). Взаимосвязь базовых психологических потребностей, академической мотивации и отчуждения от учебы обучающихся в системе высшего образования [The Relationship of Basic Psychological Needs, Academic Motivation and Alienation from Study of Students in Higher Education]. Psychological 
science and education, 25(2), 19-32. https://doi.org/10.17759/pse.2020250202

Quillien, T. (2020). When do we think that X caused Y?. Cognition, pp. 205, 104410. https://doi.org/10.1016/j. cognition.2020.104410

Shelegina, A.Үa. (2018). Онтологическая уверенность и базовые убеждения личности как предикторы психологического благополучия. [The person's ontological confidence and basic beliefs as predictors of psychological well-being]. Lomonosov Conference in Altay: fundamental problems of Science and Engineering. Bulletin of scientific articles of an international conference: electronic resource. Edited by Rodionov, E.D. Barnaul: Altay State University Publ., 15831584. Retrieved from https://elibrary.ru/item.asp?id=36972443

Shi, L., Sun, J., Wu, X., Wei, D., Chen, Q., Yang, W., ... \& Qiu, J. (2018). Brain networks of happiness: dynamic functional connectivity among the default, cognitive and salience networks relates to subjective well-being. Social cognitive and affective neuroscience, 13(8), 851-862. https://doi.org/10.1093/scan/nsy059

Ter Heide, F. J. J., Sleijpen, M., \& van der Aa, N. (2017). Posttraumatic world assumptions among treatment-seeking refugees. Transcultural psychiatry, 54(5-6), 824-839. https://doi.org/10.1177/1363461517741811

Trifonova, A. V. (2016). Вклад понятийных способностей в развитие интеллектуального ресурса личности. [Conceptual abilities contribution to person's intellectual resource development]. Psychological researches. Edited by A/L/Zhuravlev, E.A. Sergienko. Moscow: Institute of Psychology of the Russian Academy of Sciences Publ., 8, 155-166 Retrieved from https://elibrary.ru/item.asp?id=26784457

Trzebiński, J., Cabański, M., \& Czarnecka, J. Z. (2020). Reaction to the COVID-19 pandemic: the influence of meaning in life, life satisfaction, and assumptions on world orderliness and positivity. Journal of Loss and Trauma, 25(6-7), 544-557. https://doi.org/10.1080/15325024.2020.1765098

Tsvetkov, M.A. (2020). Влияние базисных убеждений на взаимодействие родителя и ребенка. [Basic beliefs influence on a parent interaction with a child]. International Electronic Scientific Journal, 3(74), 141-145. Retrieved from https:// elibrary.ru/item.asp?id=44002216

Volkova, N. N., \& Gusev, A. N. (2016). Когнитивные стили: дискуссионные вопросы и проблемы изучения. [Cognitive styles: Controversial issues and research problems]. National Psychological Journal, 2, 28-37. Retrieved from https:// elibrary.ru/item.asp?id=27536968

Ward, T., \& Plagnol, A. (2019). Cognitive psychodynamics as an integrative framework in counselling psychology and psychotherapy. Springer International Publishing. https://doi.org/10.1007/978-3-030-25823-8_7

Załuski, M. (2015). The worldview contained in declarations of police officers scheduled for psychotherapeutic treatment. [Obraz Swiata Zawart Y W Dekl Aracjach Pol Icjantów Zakwalifikowanych Naleczenie Psychot Erapeutyczne] Psychoterapia, (2), 57-70. https://doi.org/10.12740/PT/42010 